\title{
COMPETENCIAS COMUNICATIVAS Y SALUD MENTAL POSITIVA EN EL PERFIL PROFESIONAL DE LOS PROFESORES DE LA EDUCACIÓN BÁSICA DE LIMA METROPOLITANA
}

\author{
COMMUNICATION SKILLS AND POSITIVE MENTAL HEALTH IN THE \\ PROFESSIONAL PROFILE OF TEACHERS IN BASIC EDUCATION OF LIMA
}

\author{
Oswaldo Orellana M.; Lupe Garcia A.; Elisa Yanac R., Jorge Rivera M.; Julio Alvites R., Daphne Orellana \\ Garcia; Genaro Araujo S.; Patricia Canseco V., Cristina mendoza S. \\ Universidad Nacional Mayor de San Marcos, Lima, Perú \\ (Recibido el 25/09/2012, Aceptado el 30/11/2012)
}

\begin{abstract}
RESUMEN
Esta investigación selecciona dos variables contribuyentes a la configuración de un perfil profesional del profesor de la educación pública, desde la psicología, y a partir de competencias comunicativas y la de salud mental positiva. Esta última centrada en seis factores: Satisfacción Personal; Actitud Prosocial; Autocontrol; Autonomía; Resolución de problemas y autoactualización; y Habilidades de Relación Interpersonal, exploradas por la variable salud mental positiva y la competencia comunicativa, identificando los estilos de pensamiento resultantes de la dominancia cerebral hemisférica. La muestra estuvo constituida por 274 profesores de los distintos niveles de la educación básica y que laboran en el ámbito geográfico del departamento de Lima; según variables controladas que favorecen el análisis de la correlación de las variables investigadas.
\end{abstract}

Los hallazgos gruesos encontrados, precisan que los puntajes de las competencias comunicativas (pruebas 1 y 2) presentan correlaciones significativas con la salud mental positiva llegando hasta $0.197,0.190,0.67,0.175$; y en el caso contrario de los puntajes de las pruebas 3 y 4 los cuales prácticamente no muestran correlación con la salud mental positiva, lo que significa que se evidencia dominancias cruzadas de los hemisferios cerebrales que orientan la comunicación comunicativa en relación a la salud mental positiva, destacando casi uniformemente los hemisferios derecho e izquierdo.

Se concluye que hay una hegemonía del hemisferio izquierdo y cerebral superior, predisponiendo hacia un perfil lógico-racional analítico y creativo-lógico; en el primer caso permite un proceso de comunicación de tipo verbal y escrito caracterizado por un lenguaje simbólico y argumentativo ideal para la elaboración de ensayos científicos en el que priman los códigos elaborados del discurso de las ciencias. Sin embargo, es necesario anotar que dicho perfil es de carácter dogmático y reduccionista; y en el segundo permite un proceso de comunicación tanto verbal como no verbal, pues en dicho perfil se da una comunicación media entre los dos hemisferios a través del cuerpo calloso. Debido a la capacidad sinérgica existen capacidades aunque reducidas de actuar tanto en el cuerpo del ensayo científico como en la poesía, el cuento, sin embargo, es un perfil que descuida lo humanístico, lo espiritual y la gestión de la complejidad humana. 
Es importante destacar que en la salud mental positiva, específicamente el ítems 20 "Creo que soy una persona sociable" presenta correlaciones significativas y negativas con los cuatro puntajes de las pruebas de competencias comunicativas, recomendando profundizar el análisis de los resultados obtenidos en la presente investigación contrastándolos con otras investigaciones, para así contribuir a un mejor entendimiento de las competencia comunicativas con la salud mental positiva.

Palabras clave: Psicología positiva, competencia comunicativa, salud mental positiva, , estilos de pensamiento, actitudes, estrategias de afrontamiento

\begin{abstract}
This research selects two variables contributing to the configuration of a teacher profesonal profile public education, psychology, and from communication skills and positive mental health, the latter focusing on six factors: personal satisfaction Prosocial Attitude; self-control, autonomy, and self-actualization Troubleshooting, and interpersonal skills, explored by the variable positive mental health and communicative competence, identifying thinking styles resulting from cerebral hemispheric dominance. The sample consisted of 274 teachers of different levels of basic education and working in the geographical scope of the department of Lima, as controlled variables that favor the correlation analysis of the variables investigated

The findings found thick, require that scores of communication skills (tests 1 and 2) have significant correlations with positive mental health reaching $0.197,0.190,0.67,0.175$, and in the opposite case of test scores 3 and 4 which show virtually no correlation with positive mental health., which means that cross dominances evidence of the cerebral hemispheres that guide communicative communication regarding positive mental health, highlighting almost uniformly left and right hemispheres.

We conclude that there is a dominance of the left hemisphere and upper brain, did a profile predisposing logical-rational-logical analytical and creative, in the first case allows a process of verbal communication and writing characterized by a symbolic language and argumentative ideal for scientists test development that prevail in the elaborate codes of science discourse. However it is necessary to note that the profile is dogmatic and reductionist, and the second allows a process of communication both verbal and nonverbal, for in that profile gives half a communication between the two hemispheres through the corpus callosum. Because there are synergistic capacity but reduced capacity to act both in the body of scientific test as in poetry, the story is a profile yet neglecting the humanities, the spiritual and the management of human complexity.

Importantly, positive mental health, specifically item 20 "I think I'm a people person" has significant and negative correlations with the four test scores of communication skills, recommending further analysis of the results obtained in the present contrasting research with other research, thus contributing to a better understanding of the communicative competence with positive mental health
\end{abstract}

Keywords: positive psychology, communicative competence, positive mental health, thinking styles, attitudes, coping strategies 


\section{INTRODUCCIÓN}

La psicología positiva forma parte de un enfoque contemporáneo que identifica las fortalezas en las personas (valores, equilibrio socioemocional, orientación hacia metas...); contextualizando condiciones del bienestar y gestión personal de las virtudes humanas; esto último minimizado por la psicología tradicional que enfatizó en las características del malestar o déficit psicológico de las personas. Fue Martín Seligman (Universidad de Pennsylvania), activista en la década del 90 en la dirección de la Asociación Americana de psicología, que introduce los temas positivos de las personas, como interés central de la Psicología humana; así mismo Mihaly Csikszentmihalyi (director del departamento de psicología de la Universidad de Chicago) y Jahoda Jahoda (1958); esta última publicó la monografía Current concepts of positive mental health.que plantea un modelo de 6 criterios o factores generales y 16 dimensiones o factores específicos que mide la salud mental positiva.

En los últimos veinte años, dichos psicólogos han sido catalogados como fundadores de este enfoque, ejerciendo especial influencia en la denominada nueva psicología. Cabe señalar que desde los orígenes de la Psicología, los filósofos clásicos se interesaron por las características positivas de las personas, precisando que a Sócrates y Aristóteles los valorizamos como los más destacados, remitiéndonos a los escritos relacionados con su obra, utilizan el término eudaimonia, para referirse a la felicidad; posteriormente y en el siglo pasado encontramos psicólogos que abordan el tema, como Abraham Maslow y Carl Rogers, que estructuran la corriente llamada psicología humanista; llegando a la actualidad con el interés de establecer principios en el marco del método científico. Los temas más relevantes que se investigan son: emociones positivas como la felicidad, la alegría o el amor, y fortalezas como el optimismo, la creatividad, la gratitud, la sabiduría y la resiliencia. En nuestro interés sobre el tema hemos encontrado una tesis doctoral, presentada a la Universidad de Barcelona, por María Teresa Lluch Canut, titulada Construcción de una escala para evaluar la salud mental positiva (1999), inspirada en el pensamiento de la Organización Mundial de la Salud, que se plantea el eslogan salud para todos, concretada en los siguientes objetivos a) incrementar la cantidad de años de vida, b) vivir más años con una mejor calidad de vida, c) reducir las disparidades de salud entre las sociedades y las clases sociales y d) que todas las personas tengan servicios preventivos de salud disponibles, accesibles y adecuados; desafíos que orienta a la investigadora Lluch a construir un instrumento para la investigación de las condiciones de salud mental positiva y que la empleamos en la presente investigación.

El otro aspecto de la investigación está referido a la competencia comunicativa, particularmente asociadas a las habilidades de pensamiento; esto último investigada por R. Nickerson, D. Perkins y D. Smith (1985) en su obra Enseñar a pensar y la investigación perspectivas para enseñar a pensar; aspectos que los asociamos a la competencia y específicamente al perfil de competencias. La competencia la conceptuamos como la capacidad de actuar con eficiencia y satisfacción sobre un 
aspecto de la realidad personal, social, moral o simbólica, agregando que cada competencia es un aprendizaje complejo, que integra habilidades, actitudes y conocimientos. Específicamente la competencia comunicativa se aborda teniendo en cuenta el funcionamiento de la dominancia cerebral, infiriendo que ciertos mensajes son activados por el hemisferio derecho y otros por el hemisferio izquierdo, investigado por las neurociencias y destacados investigadores como: Sperry, Roger, Wolcott (1994) en la Universidad de Chicago y en general por la literatura especializada en la década del 70 del siglo pasado y posteriores, hasta la actualidad.

Sobre el perfil del profesor, tenemos la referencia publicada por el CONEAU (2008) en el modelo de calidad, y en donde considera que los buenos desempeños deben de expresarse en perfil de competencias profesionales, bajo la responsabilidad de los colegios profesionales.

\section{Planteamiento del estudio}

La investigación responde a una exigencia técnica y profesional, que busca relacionar variables involucradas en el desempeño laboral y la salud mental positiva; destacando que la psicología aporta con características positivas al perfil de competencia del profesor. Más aún cuando en la actualidad se debate la evaluación del desempeño docente como una alternativa frente a las evaluaciones "memorísticas" en una prueba de 180 minutos, que parcialmente califica el conocimiento objetivo de la calidad profesional y personal del profesor.

En las líneas de investigación del Instituto de Investigaciones Psicológicas de la Universidad Nacional Mayor de San Marcos, una de las primeras prioridades se encuentra en investigar los temas centrales de la educación, siendo el perfil de competencias del profesor, uno de ellos.

Declaraciones nacionales e internacionales, tales como las metas para el siglo XXI, de los ministros de Educación en El Salvador (19 de mayo de 2008), las intervenciones del Consejo Nacional de Educación (27 de octubre 2010) que dio a conocer al país las "propuestas de políticas de Educación del CNE Banderas para el periodo 2011-2016", coinciden que el profesor debe estar preparado para orientar de manera integral a las nuevas generaciones, en beneficio de la instauración de programas de conductas saludables. Asumimos que este debe expresarse en su perfil de cualidades positivas.

\section{Marco teórico}

Una referencia para abordar la salud mental positiva la tenemos en Jahoda (1958), quien propone un modelo con determinadas directrices orientadas a potenciar los recursos y las habilidades personales, concretados en seis criterios de salud mental, A dicha conclusión se llega después de haber deslindado con muchos enfoques que la relacionan con la ausencia de enfermedad y es específicamente con ausencia de trastorno mental, como lo señala la propia autora; afirmando que este criterio podría ser necesario, pero no suficiente. Del mismo modo se aborda el criterio estadístico y el criterio sociocultural. De otro lado algunos asocian la salud mental 
con la felicidad y el bienestar, y esto podría ser correcto, si es que se presenta como una disposición a encontrarse bien, por la armonía que existiera entre las expectativas que se tiene a la vida y lo que la vida ofrece a las personas, sin que esto sea algo transitorio o una respuesta emocional.

Según $\mathrm{M}^{\mathrm{a}}$ Teresa Lluch Canut, el modelo de salud mental positiva de Jahoda surge en Estados Unidos cuando, en 1955, se constituye la Joint Commission Mental Illness and Health (Comisión Conjunta para la Enfermedad y la Salud Mental) con el objetivo de llevar a cabo un estudio integral de la salud mental. Esta comisión, de carácter multidisciplinar, generó diferentes estudios, entre los cuales se halla el de Jahoda (1958), a quien se le encomendó investigar y profundizar en el concepto de salud mental positiva, y agrega los resultados del trabajo global de dicha comisión fueron presentados en un informe final (Actionfor Mental Health), en 1961, que sirvió de base para orientar las nuevas políticas de salud mental. Así, en 1963 se aprobó la Ley de Servicios para el Retraso Mental y Organización de Centros Comunitarios de Salud Mental (Mental RetardationFacilities and Community Mental Health Centers Construction Act) que refleja las recomendaciones fundamentales de la comisión conjunta. En este sentido, se hace hincapié en la concepción multicausal del trastorno mental y en la necesidad de conocer y enfatizar los factores que contribuyen a mantener y potenciar la salud mental del ser humano.

En este contexto y bajo estas consideraciones surge el planteamiento de los seis criterios de salud mental positiva, y son los siguientes:

- Actitudes hacía si mismo

- Crecimiento y auto actualización

- Integración

- Autonomía; y

- Percepción de la realidad

- Dominio del entorno

Y para una mejor orientación exponemos, el contenido de cada uno de ellos:

\section{Actitudes hacia sí mismo}

Se refiere a la reacción que tiene la persona en relación consigo mismo, implicando la autopercepción, auto aceptación, aceptando sus propias limitaciones y posibilidades, autoconfianza y/o auto dependencia, expresados en las formas que las personas aprenden a vivir consigo mismas; aceptando sus propias limitaciones y posibilidades. $\mathrm{M}^{\mathrm{a}}$ Teresa Lluch Canut sostiene que la autoconfianza engloba la autoestima y el auto respeto e implica que la persona se considera a sí misma buena, fuerte y capaz. Por último, la auto dependencia incluye el concepto de autoconfianza pero enfatiza la independencia de los demás y la propia iniciativa, reforzando la idea de que uno depende fundamentalmente de sí mismo y de sus propios criterios. 
Jahoda (1958) identifica cuatro dimensiones de las actitudes hacia sí mismo; estas son las siguientes (1) Accesibilidad del yo a la conciencia (2) Concordancia yo real-yo ideal; (3) Autoestima; y (4) Sentido de identidad; los mismos que en su contenido y extensión guardan una complejidad de la mismidad; por ejemplo, no es lo mismo el autoconcepto con el autonocimiento, ambos están relacionados, pero, mientras que el primero tiene una carga inmensa de valores y aspectos comportamentales, el autonocimiento es fundamentalmente un proceso cognitivo, que influye hegemónicamente en la salud mental, por cuanto ejerce un conocimiento genuino sobre la persona, implicado en nuestro caso de estar bien. La concordancia yo real-yo ideal involucra una autopercepción de lo que es la persona y lo que podría ser, implicando de una manera directa el autoconcepto y la autoaceptación. De la casuística clínica se obtiene que los trastornos de personalidad comprometidos con esta dimensión, se debe a las dificultades para elaborar una coherencia entre lo que es la persona y lo que podría ser, expresados en temores y/o miedos en ejercer y alcanzar las metas personales; convirtiéndose por lo tanto un indicador de salud mental positiva la autoaceptación adecuadamente elaborada que conduce a un desarrollo personal óptimo.

Lo anterior contextualiza la autoestima, referido a los sentimientos que uno tiene con respecto a sí mismo. Teresa Lluch Canut afirma que la salud mental implica una aceptación global del sí mismo, con todos los defectos y deficiencias personales, es decir, incluyendo aquellos aspectos de los cuales uno no se siente orgulloso o satisfecho.

Finalmente, el sentido de identidad es un atributo integrador de sí mismo, en los aspectos cognitivos, de claridad de la imagen, sobre la propia persona.

\section{Crecimiento y auto actualización}

Es sinónimo de autorrealización personal y se refiere al protagonismo de la vida consigo misma, en dos aspectos, (1) como un principio general de vida; y (2) como un criterio de salud mental positiva. Esto quiere decir que la persona debe tener las energías para vivir, para ser algo en la vida, que es lo que configura la autoactualización, de proyectarse hacia niveles superiores de realización personal, como criterio de salud mental positiva; es decir, gestión personal de las metas que se plantea en la vida.

\section{Integración}

Se refiere a todos los procesos y atributos de la persona, que en la salud mental positiva implican tres aspecto(1) Equilibrio psíquico, (2) Filosofía personal sobre la vida; y (3)Resistencia al estrés (Resistenceto stress). El equilibrio psíquico es entendido bajo la orientación psicoanalítica, es decir, la integración, como criterio de salud mental, que implica un equilibrio entre las instancias psicológicas del ello, el yo y el super yo o entre los fenómenos psíquicos conscientes, preconscientes e inconscientes. La filosofía personal sobre la vida, como un proceso de reflexión cognitiva sobre el significado de la vida y la construcción del desarrollo personal; la resistencia al estrés, referido al estilo personal, para afrontar las situaciones estresantes de la vida. 
Como criterio de salud mental positiva se interpreta como la capacidad de afrontamiento hacia la ansiedad y la frustración que desarrollan las personas en la vida, y que les permite el manejo de las tensiones ocasionadas en dichas situaciones.

\section{Autonomía}

Esta dimensión establece la vinculación de la persona con el medio ambiente, referida fundamentalmente al grado de dependencia/independencia frente a las influencias sociales, y se convierte en un indicador del estado de la salud mental. La persona psicológicamente sana tiene una cierta autonomía y no depende fundamentalmente del mundo y de los demás. Se identifican dos aspectos fundamentales: Autorregulación y conducta independiente. La autoregulación se presenta como una capacidad para modelar la autonomía, que le permite un crecimiento personal autosostenido por un sistema de creencias, valores, necesidades y metas personales, que favorecen la conducta independiente, obteniendo equilibrio emocional, convirtiéndose en indicadores de la salud mental positiva.

\section{Percepción de la realidad}

Se refiere a la forma cómo construye la realidad, para lo cual se consideran dos aspectos: (1) Percepción objetiva; y (2) Empatía o sensibilidad social. Jahoda (1958) considera la percepción objetiva como un criterio íntimamente relacionado con la adaptación a la realidad, puesto que la adaptación está basada en la percepción correcta del ambiente. La empatía es la percepción de los sentimientos y de las actitudes de los otros y configura un criterio independiente.

\section{El dominio del entorno}

Como su nombre lo expresa, es la capacidad para manejarse en una realidad concreta, con un buen desempeño personal en sus propósitos. Se aborda en dos aspectos fundamentales: (1) el éxito (que enfatiza el logro o resultado) y (2) la adaptación (que enfatiza el proceso). Dentro de este criterio Jahoda distingue seis dimensiones íntimamente relacionadas: (1) Satisfacción sexual; (2) Adecuación en el amor, el trabajo y el tiempo libre; (3) Adecuación en las relaciones interpersonales; (4)Habilidad para satisfacer las demandas del entorno; (5) Adaptación y Ajuste; y (6) Resolución de problemas.

La satisfacción sexual está relacionada con la habilidad para experimentar placer sexual y para mantener relaciones sexuales gratificantes. La adecuación en el amor, el trabajo y el tiempo libre, son tres aspectos que se relacionan con la salud mental positiva, pues integra actividades que requieren un ajuste estable en la vida de las personas. La adecuación en las relaciones interpersonales implica la capacidad para interaccionar con los demás, manteniendo relaciones interpersonales satisfactorias y afectivas. La habilidad para satisfacer las demandas del entorno es la capacidad para dar una respuesta válida a las necesidades de una situación. Los requerimientos sociales están en función del entorno y, por tanto, deben definirse y valorarse específicamente en cada contexto. La adaptación implica la capacidad para alcanzar un equilibrio entre las necesidades y habilidades del individuo y la realidad. Un término que se utiliza con mayor frecuencia que el de adaptación es 
el de ajuste, que puede entenderse bien como un concepto pasivo de aceptación de lo que la vida brinda o bien como sinónimo de adaptación con una connotación activa. La resolución de problemas engloba tanto el procedimiento como el resultado en la búsqueda de soluciones. Una forma de entender la resolución de problemas es poniendo el énfasis en el producto final: la solución. Si se aplica este criterio a los problemas reales, el éxito es un criterio de salud mental positiva.

De otro lado, las competencias comunicativas son evaluadas por el cuestionario de Carlos Jiménez, que enfatiza en los estilos de pensamiento, asociados con la especialización de la dominancia cerebral (Magisterio, 2003), compuesto por 40 preguntas, que goza con las características psicométricas de validez y confiabilidad.

Se ha seleccionado el formato cuatro de competencias lingüísticas

(1) Cuadrante A; (2) Cuadrante B; (3) Cuadrante C ; (4) Cuadrante D

\section{Hipótesis}

Las competencias comunicativas se correlacionan positivamente con la salud mental positiva.

\section{MÉTODO}

El método empleado en la presente investigación es el correlacional y tiene como objetivo precisar las asociaciones establecidas en las variables involucradas, en su condición de variables correlacionadas y de control, según las siguientes especificaciones:

\section{Diseño de investigación}

Descriptivo correlacional y comparativo

\section{Muestreo}

La muestra seleccionada es probabilística estratificada.

\section{Variables relacionadas}

Competencias Comunicativas expresadas por el funcionamiento del cerebro a través de estilos de pensamiento y que miden las siguientes estructuras

1. Cuadrante A

2. Cuadrante B

3. Cuadrante $\mathrm{C}$

4. Cuadrante D

Salud Mental Positiva, evaluadas por la escala de Teresa Lluch (1999) que privilegia seis factores :

1. Satisfacción Personal;

2. Actitud Pro social; 
3. Autocontrol;

4. Autonomía;

5. Resolución de problemas y autoactualización; y

6. Habilidades de Relación Interpersonal

\section{Variables controladas}

(1) Edad; (2) Género (3) Formación profesional: (a) Universitaria en Pedagogía (Educación); (b) Superior pedagógica (c) Superior tecnológica (d) Maestría (e) Doctorado (4) Años de servicios docentes (5) Estado civil (6) Residencia (7) Ejercicio Docente (8) Especialidad.

\section{Instrumentos de Investigación}

Cuestionario de Competencias Comunicativas de Carlos Jiménez, de aplicación individual y colectiva, con una duración aproximada de 30 minutos, basado en planteamientos heurísticos en la intervención de estilos de pensamiento y dominancia cerebral en los sistemas de comunicación, publicado en la editorial magisterio en el año 2003.

Cuestionario de Salud Mental Positiva, de aplicación individual y colectiva, con una duración aproximada de 20 minutos, compuesto por seis factores generales, y con 39 ítems, estadísticamente el instrumento cuenta con una fiabilidad entre 0.71 y 091 , y error típico entre 0.09 y 0.22 (coeficiente alfa). En cuanto a la validez, cuenta con la validez de contenido y validez de constructo.

Muestra: La muestra estuvo compuesta por 274 docentes, mostrando las referencias en tablas y figuras.

\section{RESULTADOS}

La distribución por grupo de edades de las personas evaluadas se puede ver en la Figura N. ${ }^{\circ}$ 1. La mayor cantidad de profesores se sitúan en los grupos de edades entre los 20 y menos de 40 años de edad, representando el $65,1 \%$ en total.

Figura N. ${ }^{\circ} 1$

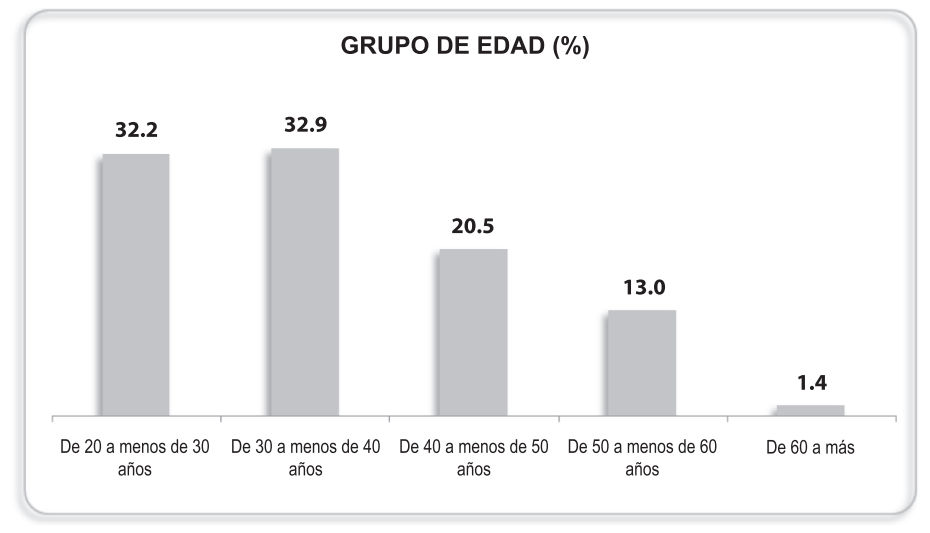

Fuente: Evaluación para conocer las competencias comunicativas y salud mental positiva de los profesores de Lima Metropolitana 
TABLA N 1: GRUPO DE EDAD

\begin{tabular}{|l|c|c|c|c|}
\hline & Frecuencia & Porcentaje & Porcentaje válido & $\begin{array}{c}\text { Porcentaje } \\
\text { acumulado }\end{array}$ \\
\hline De 20 a menos de 30 años & 47 & 17.2 & 32.2 & 32.2 \\
De 30 a menos de 40 años & 48 & 17.5 & 32.9 & 65.1 \\
De 40 a menos de 50 años & 30 & 10.9 & 20.5 & 85.6 \\
De 50 a menos de 60 años & 19 & 6.9 & 13.0 & 98.6 \\
De 60 a más & 2 & 0.7 & 1.4 & 100.0 \\
\hline Total & 146 & 53.3 & $\mathbf{1 0 0 . 0}$ & \\
\hline No contesta & 128 & 46.7 & & \\
\hline Total & $\mathbf{2 7 4}$ & $\mathbf{1 0 0 . 0}$ & & \\
\hline
\end{tabular}

Fuente: Evaluación para conocer las competencias comunicativas y salud mental positiva de los profesores de Lima Metropolitana

Con respecto a la distribución por género, vemos que más de la mitad de profesores son de género femenino, representando el $64,5 \%$ y el 35,5\% al género masculino.

TABLA N 2: GÉNERO

\begin{tabular}{|l|c|c|c|c|}
\hline & Frecuencia & Porcentaje & Porcentaje válido & $\begin{array}{c}\text { Porcentaje } \\
\text { acumulado }\end{array}$ \\
\hline Masculino & 88 & 32.1 & 35.5 & 35.5 \\
Femenino & 160 & 58.4 & 64.5 & 100.0 \\
\hline Total & 248 & 90.5 & 100.0 & \\
\hline No contesta & 26 & 9.5 & & \\
Total & $\mathbf{2 7 4}$ & 100.0 & & \\
\hline
\end{tabular}

Figura $\mathrm{N}^{\circ} 2$

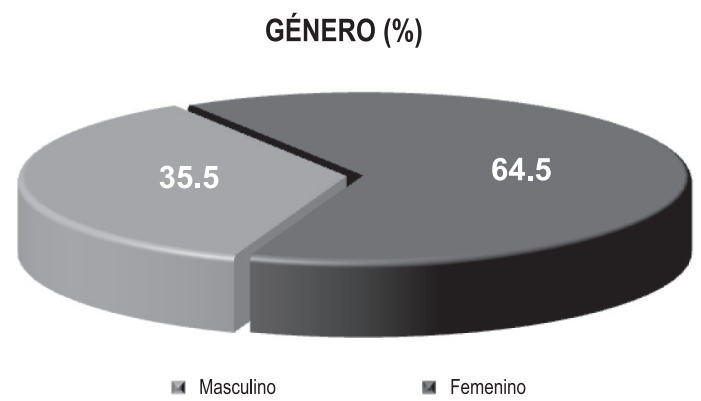

Fuente: Evaluación para conocer las competencias comunicativas y salud mental positiva de los profesores de Lima Metropolitana

Sobre el ejercicio docente de los protesores evaluados, en su mayoría, es el nivel secundario que representa el $41,7 \%$, los profesores de primaria son un $31,6 \%$ seguido por la educación superior $(17,1 \%)$ y el nivel inicial $9.6 \%$.

TABLA N³: EJERCICIO DOCENTE

\begin{tabular}{|l|c|c|c|c|}
\hline & Frecuencia & Porcentaje & Porcentaje válido & $\begin{array}{c}\text { Porcentaje } \\
\text { acumulado }\end{array}$ \\
\hline Inicial & 22 & 8.0 & 9.6 & 9.6 \\
Primaria & 72 & 26.3 & 31.6 & 41.2 \\
Secundaria & 95 & 34.7 & 41.7 & 82.9 \\
Superior & 39 & 14.2 & 17.1 & 100.0 \\
\hline Total & $\mathbf{2 2 8}$ & 83.2 & $\mathbf{1 0 0 . 0}$ & \\
\hline No contesta & 46 & 16.8 & & \\
\hline Total & $\mathbf{2 7 4}$ & $\mathbf{1 0 0 . 0}$ & & \\
\hline
\end{tabular}


Figura $\mathrm{N}^{\circ} 3$

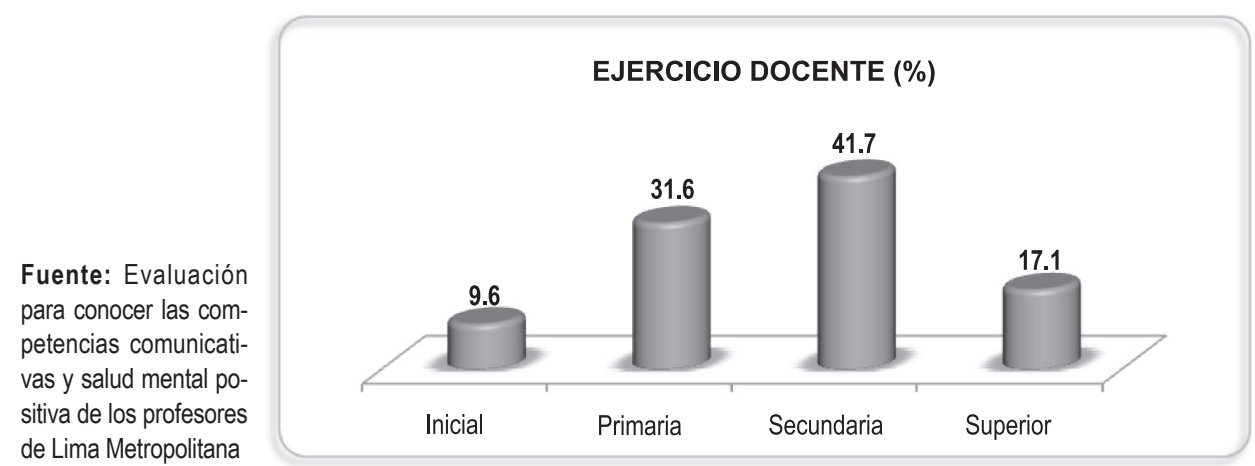

Según el tipo de institución educativa donde laboran los docentes, se tiene que el $53,7 \%$ labora en instituciones educativas privadas, $42,4 \%$ en públicas y $3,3 \%$ en otro tipo de institución.

TABLA N 4: INSTITUCIÓN EDUCATIVA DONDE LABORA

\begin{tabular}{|l|c|c|c|c|}
\hline & Frecuencia & Porcentaje & Porcentaje válido & $\begin{array}{c}\text { Porcentaje } \\
\text { acumulado }\end{array}$ \\
\hline Privada & 123 & 44.9 & 53.7 & 53.7 \\
Pública & 97 & 35.4 & 42.4 & 96.1 \\
Otro & 9 & 3.3 & 3.9 & 100.0 \\
\hline Total & 229 & 83.6 & 100.0 & \\
\hline No contesta & 45 & 16.4 & & \\
Total & 274 & 100.0 & & \\
\hline
\end{tabular}

Figura $\mathrm{N}^{\circ} 4$

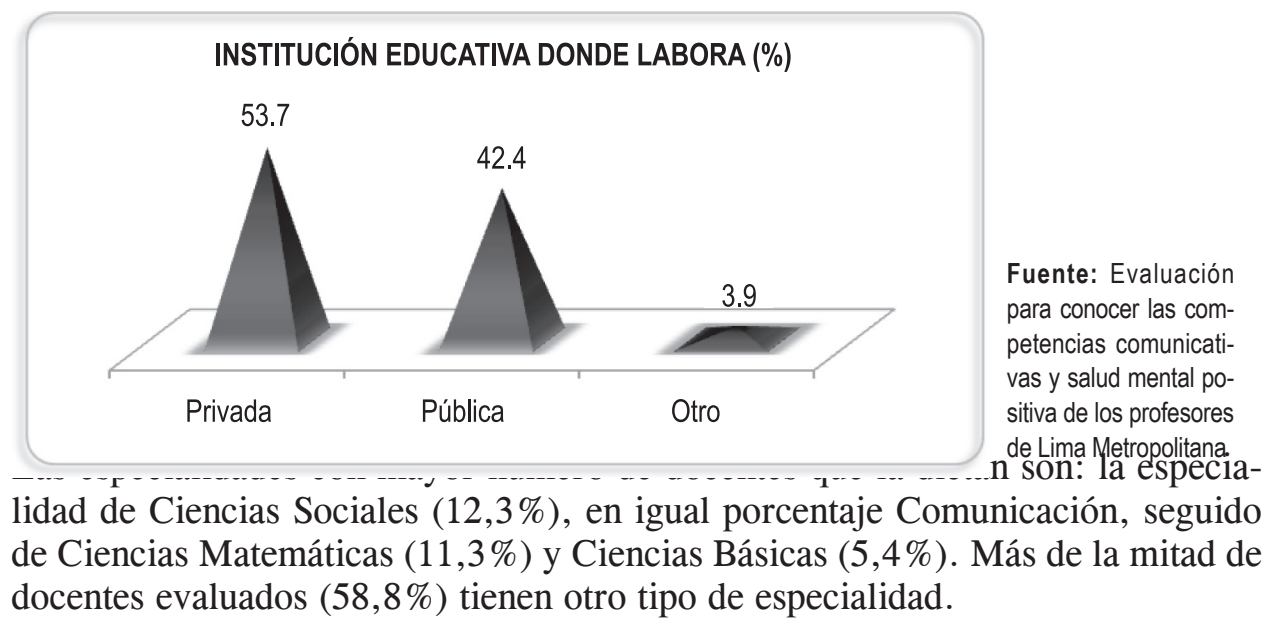


TABLA N 5 : ESPECIALIDAD

\begin{tabular}{|l|c|c|c|c|}
\hline & Frecuencia & Porcentaje & Porcentaje válido & $\begin{array}{c}\text { Porcentaje } \\
\text { acumulado }\end{array}$ \\
\hline Ciencias básicas & 11 & 4.0 & 5.4 & 5.4 \\
Ciencias sociales & 25 & 9.1 & 12.3 & 17.6 \\
Ciencias matemáticas & 23 & 8.4 & 11.3 & 28.9 \\
Comunicación & 25 & 9.1 & 12.3 & 41.2 \\
Otros & 120 & 43.8 & 58.8 & 100.0 \\
\hline Total & $\mathbf{2 0 4}$ & 74.5 & $\mathbf{1 0 0 . 0}$ & \\
\hline No contesta & 70 & 25.5 & & \\
\hline Total & $\mathbf{2 7 4}$ & $\mathbf{1 0 0 . 0}$ & & \\
\hline
\end{tabular}

Figura $\mathrm{N}^{\circ} 5$

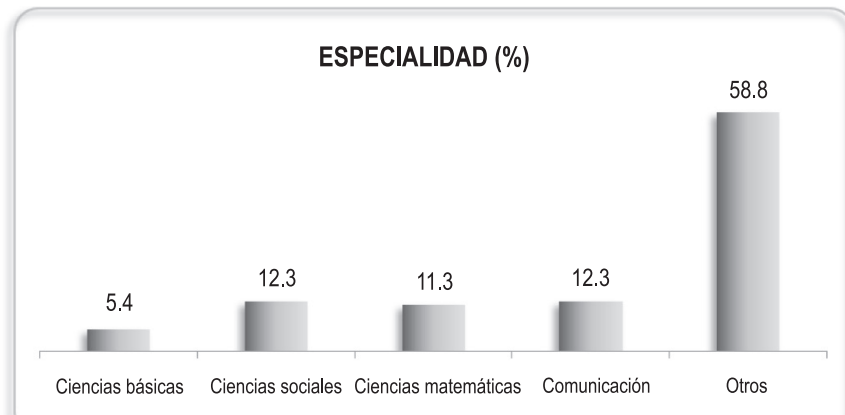

Fuente: Evaluaciòn para conocer las competencias comunicativas y salud mental positiva de los profesores de Lima Metropolitana

Lon respecto al estado civil ae ios protesores podemos observar, en la figura $\mathrm{N}^{\circ}$ 5 , que más de la mitad de profesores $(56,4 \%)$ son solteros, los casados representan el $32,3 \%$, los convivientes un $8,9 \%$ y los divorciados $2,3 \%$.

TABLA N 6: ESTADO CIVIL

\begin{tabular}{|l|c|c|c|c|}
\hline & Frecuencia & Porcentaje & Porcentaje válido & $\begin{array}{c}\text { Porcentaje } \\
\text { acumulado }\end{array}$ \\
\hline Soltero & 145 & 52.9 & 56.4 & 56.4 \\
Casado & 83 & 30.3 & 32.3 & 88.7 \\
Conviviente & 23 & 8.4 & 8.9 & 97.7 \\
Divorciado & 6 & 2.2 & 2.3 & 100.0 \\
\hline Total & $\mathbf{2 5 7}$ & 93.8 & $\mathbf{1 0 0 . 0}$ & \\
\hline No contesta & 17 & 6.2 & & \\
Total & $\mathbf{2 7 4}$ & $\mathbf{1 0 0 . 0}$ & & \\
\hline
\end{tabular}

Figura $N^{\circ} 6$

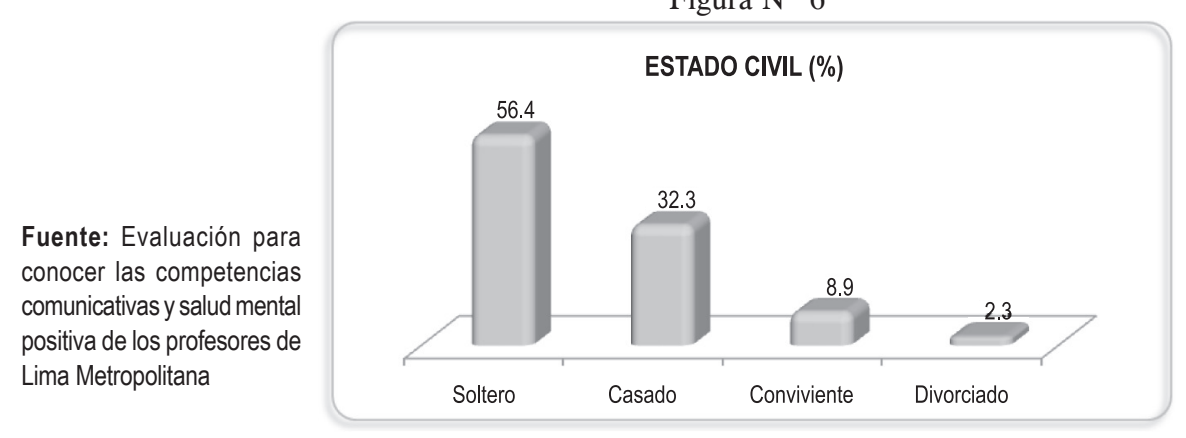


La mitad de docentes reside en Lima ciudad (50,6\%), 28,5\% en la sierra, 15,3\% en la costa y 5,6\% en Lima provincias.

TABLA N 7: RESIDENCIA

\begin{tabular}{|l|c|c|c|c|}
\hline & Frecuencia & Porcentaje & Porcentaje válido & $\begin{array}{c}\text { Porcentaje } \\
\text { acumulado }\end{array}$ \\
\hline Lima ciudad & 126 & 46.0 & 50.6 & 50.6 \\
Lima provincias & 14 & 5.1 & 5.6 & 56.2 \\
Costa & 38 & 13.9 & 15.3 & 71.5 \\
Sierra & 71 & 25.9 & 28.5 & 100.0 \\
\hline No contesta & $\mathbf{2 5}$ & 9.1 & & \\
\hline Total & 249 & 90.9 & & 100 \\
Total & $\mathbf{2 7 4}$ & $\mathbf{1 0 0 . 0}$ & & \\
\hline
\end{tabular}

Figura $\mathrm{N}^{\circ} 7$

\section{RESIDENCIA (\%)}

Fuente: Evaluación para conocer las competencias comunicativas y salud mental positiva de los profesores de Lima Metropolitana

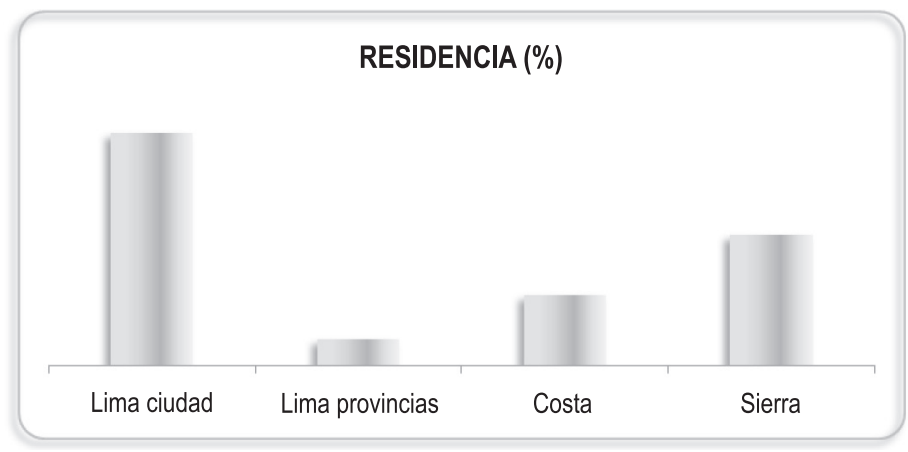

Los docentes que cumplen una función tutorial representan el 48,6\%, mientras que el 51,4\% no hacen la función tutorial.

TABLA N 8: FUNCIÓN DE TUTORÍA

\begin{tabular}{|l|c|c|c|c|}
\hline & Frecuencia & Porcentaje & Porcentaje válido & $\begin{array}{c}\text { Porcentaje } \\
\text { acumulado }\end{array}$ \\
\hline Soy tutor & 87 & 31.8 & 48.6 & 48.6 \\
No soy tutor & 92 & 33.6 & 51.4 & 100.0 \\
\hline Total & $\mathbf{1 7 9}$ & 65.3 & $\mathbf{1 0 0 . 0}$ & \\
\hline No contesta & 95 & 34.7 & & \\
Total & $\mathbf{2 7 4}$ & $\mathbf{1 0 0 . 0}$ & & \\
\hline
\end{tabular}

Figura $\mathrm{N}^{\circ} 8$

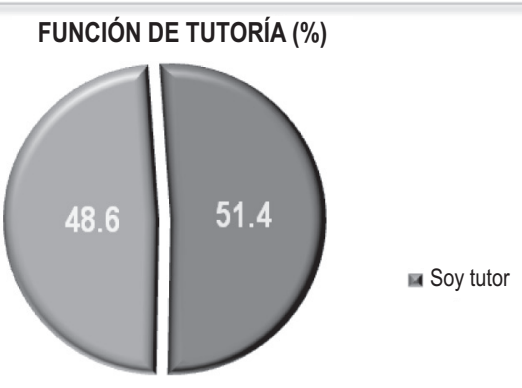

Fuente: Evaluación para conocer las competencias comunicativas y salud mental positiva de los profesores de Lima Metropolitana 
En cuanto a la formación profesional del docente, el 45,3\% tiene estudios superiores no universitarios, el 26,7\% está formado en superior pedagógico, mientras que en porcentajes menores se han formado en superior tecnológico, posgrado universitario, pos título universitario, segunda especialidad y maestría.

TABLA N 9: FORMACIÓN PROFESIONAL

\begin{tabular}{|l|c|c|c|c|}
\hline & Frecuencia & Porcentaje & Porcentaje válido & $\begin{array}{c}\text { Porcentaje } \\
\text { acumulado }\end{array}$ \\
\hline Superior no universitaria & 73 & 26.6 & 45.3 & 45.3 \\
Posgrado universitario & 14 & 5.1 & 8.7 & 54.0 \\
Postítulo universitario & 5 & 1.8 & 3.1 & 57.1 \\
Superior pedagógico & 43 & 15.7 & 26.7 & 83.9 \\
Maestría & 4 & 1.5 & 2.5 & 86.3 \\
Segunda especialidad & 5 & 1.8 & 3.1 & 89.4 \\
Superior tecnológico & 17 & 6.2 & 10.6 & 100.0 \\
\hline Total & 161 & 58.8 & 100.0 & \\
\hline No contesta & 113 & 41.2 & &
\end{tabular}

Figura $\mathrm{N}^{\circ} 9$

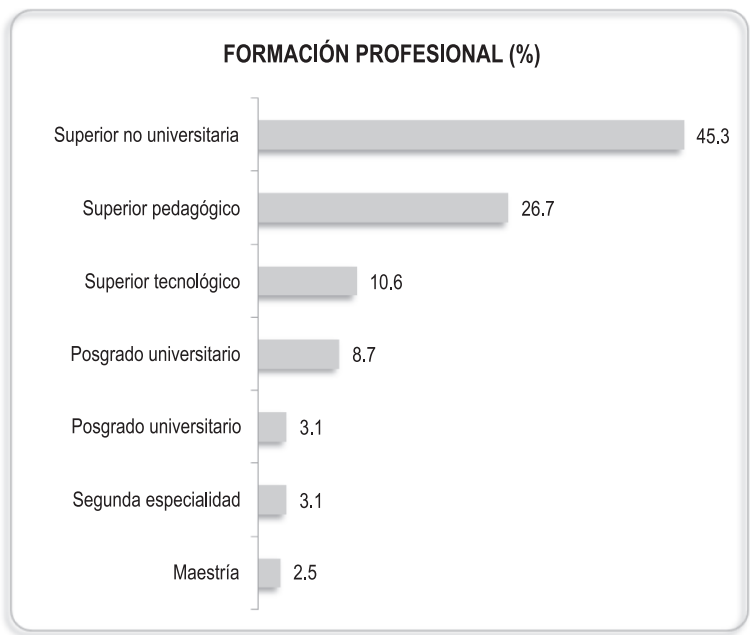

Fuente: Evaluación para conocer las competencias comunicativas y salud mental positiva de los profesores de Lima Metropolitana

Los años de servicio del docente está comprendido entre los cero y cinco años con un $47,2 \%$ de representatividad, seguido de los docentes que ya tienen entre seis y diez años de servicio, seguido de los que tienen entre 21 y 25 años, luego de 11 a 15 años, de 16 a 20 años y finalmente los docentes que tienen más de 26 años de servicio que representan el 5,2\%.

\begin{tabular}{|l|c|c|c|c|}
\hline & TABLA N 10: AÑOS DE SERVICIO $^{\text {Porcentaje }}$ \\
\hline De 0 a 5 años & Frecuencia & Porcentaje & Porcentaje válido & $\begin{array}{c}\text { Pocumulado } \\
\text { acumul| }\end{array}$ \\
De 6 a 10 años & 109 & 39.8 & 47.2 & 47.2 \\
De 11 a 15 años & 43 & 15.7 & 18.6 & 65.8 \\
De 16 a 20 años & 24 & 8.8 & 10.4 & 76.2 \\
de 21 a 25 años & 15 & 5.5 & 6.5 & 82.7 \\
Más de 26 años & 28 & 10.2 & 12.1 & 94.8 \\
Total & 12 & 4.4 & 5.2 & 100.0 \\
\hline No contesta & $\mathbf{2 3 1}$ & 84.3 & $\mathbf{1 0 0 . 0}$ & \\
Total & $\mathbf{4 3}$ & 15.7 & & \\
\hline
\end{tabular}


Figura $\mathrm{N}^{\circ} 10$

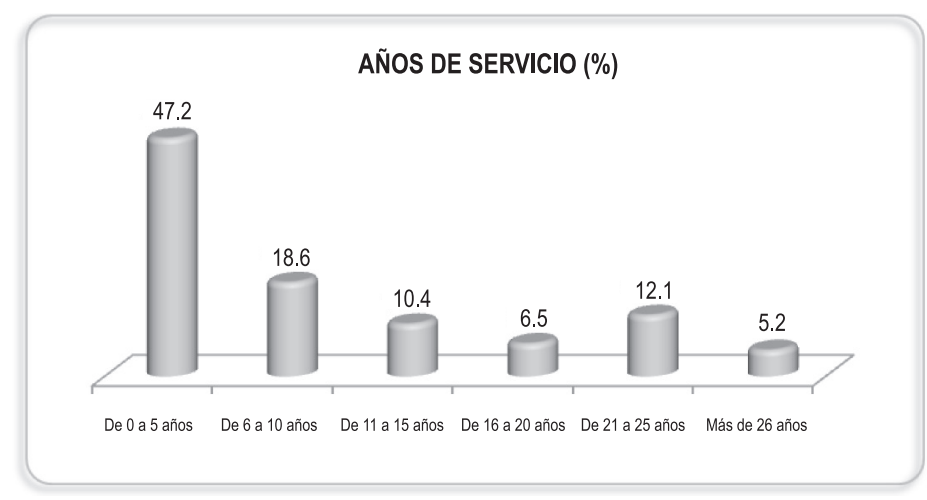

Fuente: Evaluación para conocer las competencias comunicativas y salud mental positiva de los profesores de Lima Metropolitana

El 68\% de los docentes desarrollan su labor en el área urbana, 17,8\% en el área urbana rural, el $8,2 \%$ lo hace en el área urbana marginal y un 5,9\% desarrolla su labor en otro tipo de área.

TABLA No 11: ÁREA DE TRABAJO

\begin{tabular}{|l|c|c|c|c|}
\hline & Frecuencia & Porcentaje & Porcentaje válido & $\begin{array}{c}\text { Porcentaje } \\
\text { acumulado }\end{array}$ \\
\hline Urbana & 149 & 54.4 & 68.0 & 68.0 \\
Urbana marginal & 18 & 6.6 & 8.2 & 76.3 \\
Urbana rural & 39 & 14.2 & 17.8 & 94.1 \\
Otros & 13 & 4.7 & 5.9 & 100.0 \\
\hline Total & 219 & 79.9 & 100.0 & \\
\hline No contesta & 55 & 20.1 & & \\
Total & 274 & 100.0 & & \\
\hline
\end{tabular}

Figura $N^{\circ} 11$

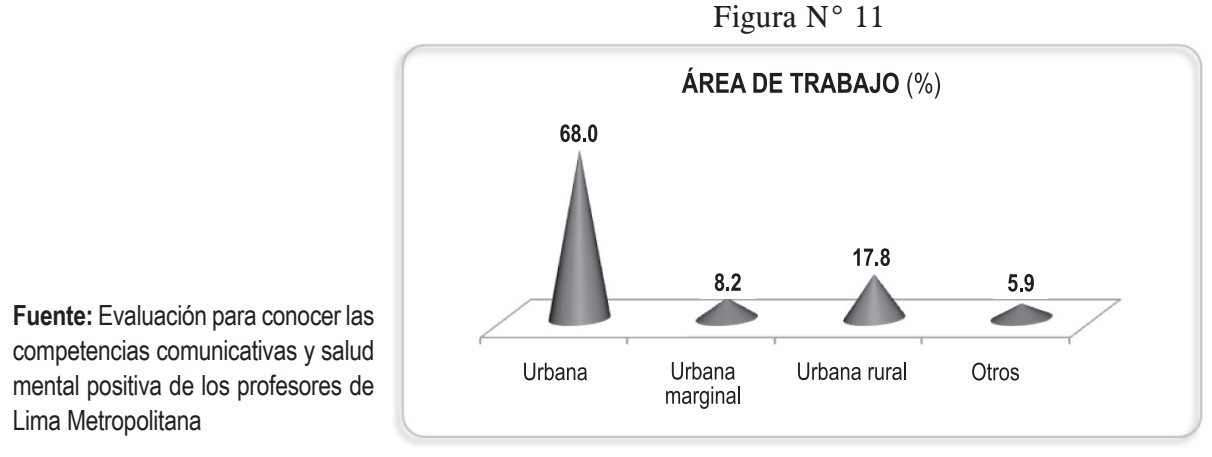

Luego de haber descrito a los docentes evauados de Lima Metropolitana, pasamos a dar los resultados obtenidos de los cuestionarios aplicados.

A continuación se muestran los resultados obtenidos de las 20 preguntas hechas en el primer cuestionario, referido a la salud mental positiva donde las respuestas están medidas en la siguiente escala: 
1: Siempre o casi siempre

2: A menudo

3: Algunas veces

4: Nunca

Figura $\mathrm{N}^{\circ} 12$

\section{ME RESULTA ESPECIALMENTE DIFÍCIL ACEPTAR A LOS OTROS CUANDO TIENEN ACTITUDES DISTINTAS A LAS MÍAS (\%)}

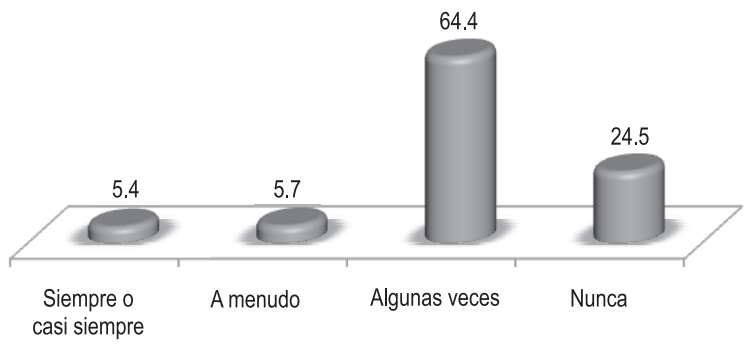

Fuente: Evaluación para conocer las competencias comunicativas y salud mental positiva de los profesores de Lima Metropolitana

Figura $\mathrm{N}^{\circ} 13$

\section{LOS PROBLEMAS ME BLOQUEAN FÁCILMENTE (\%)}

59.2

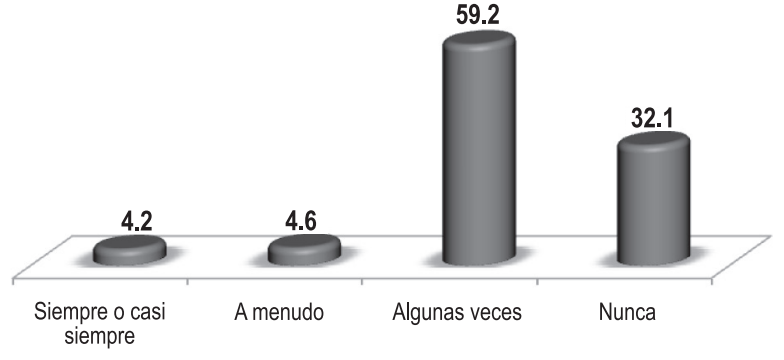

Figura $\mathrm{N}^{\circ} 14$

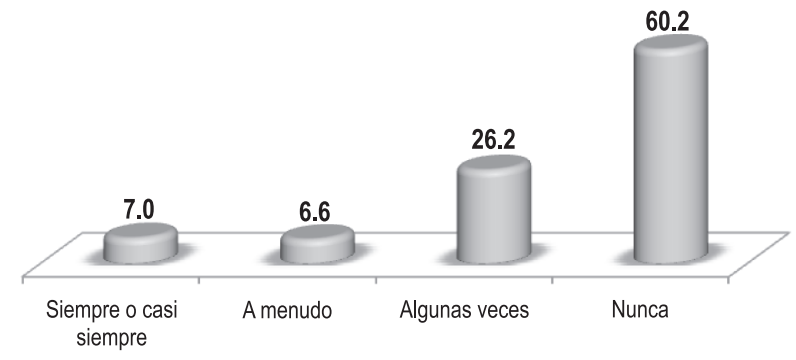

ME RESULTA ESPECIALMENTE DIFÍCIL ESCUCHAR A LAS

PERSONAS QUE ME CUENTAN SUS PROBLEMAS (\%)

Fuente: Evaluación para conocer las competencias comunicativas y salud mental positiva de los profesores de Lima Metropolitana

Fuente: Evaluación para conocer las competencias comunicativas y salud mental positiva de los profesores de Lima Metropolitana 
Figura $\mathrm{N}^{\circ} 15$

\section{ME GUSTO COMO SOY (\%)}

Fuente: Evaluación para conocer las competencias comunicativas y salud mental positiva de los profesores de Lima Metropolitana

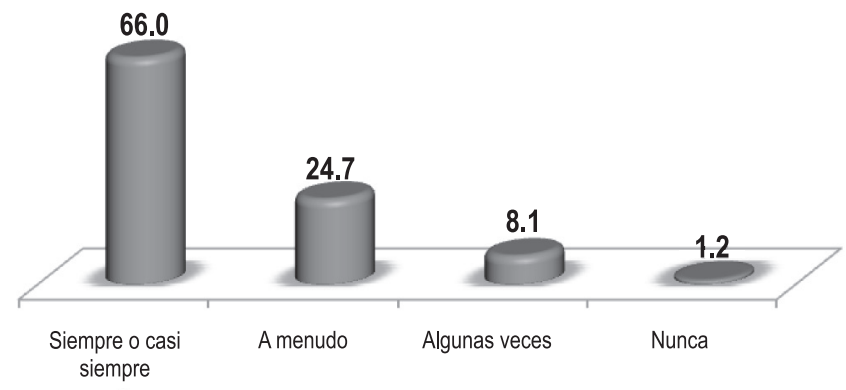

Figura $\mathrm{N}^{\circ} 16$

\section{SOY CAPAZ DE CONTROLARME CUANDO EXPERIMENTO EMOCIONES NEGATIVAS (\%)}

Fuente: Evaluación para conocer las competencias comunicativas y salud mental positiva de los profesores de Lima Metropolitana

Figura $\mathrm{N}^{\circ} 17$

\section{ME SIENTO A PUNTO DE EXPLOTAR (\%)}

Fuente: Evaluación para conocer las competencias comunicativas y salud mental positiva de los profesores de Lima Metropolitana

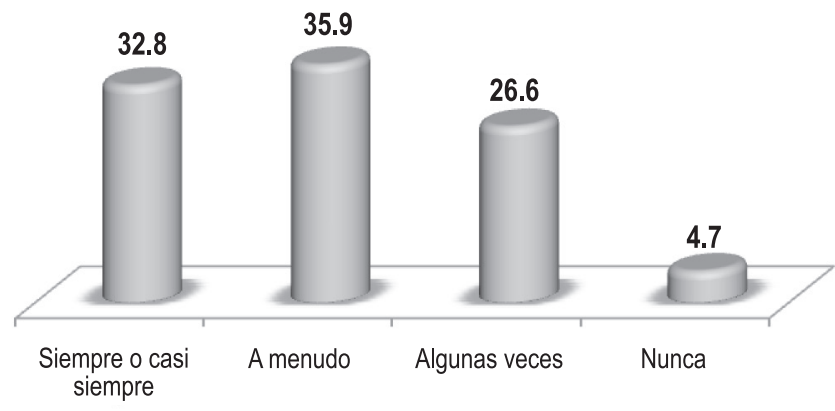


Figura $\mathrm{N}^{\circ} 18$

PARA MÍ, LA VIDA ES ABURRIDA Y MONÓTONA (\%)

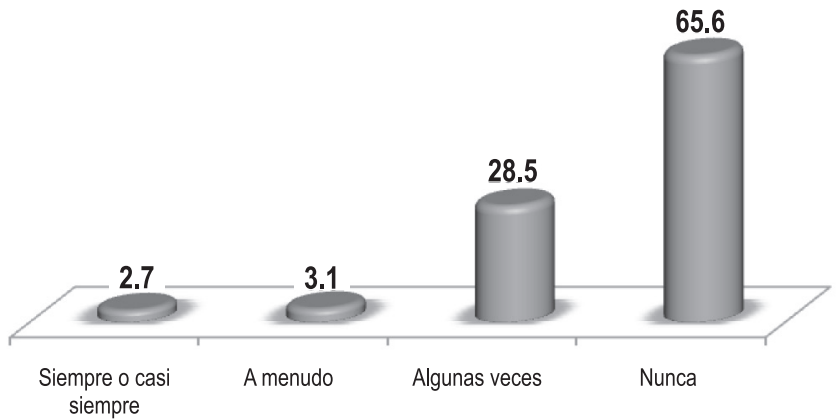

Fuente: Evaluación para conocer las competencias comunicativas y salud mental positiva de los profesores de Lima Metropolitana

Figura $\mathrm{N}^{\circ} 19$

\section{ME RESULTA ESPECIALMENTE DIFÍCIL DAR APOYO EMOCIONAL (\%)}

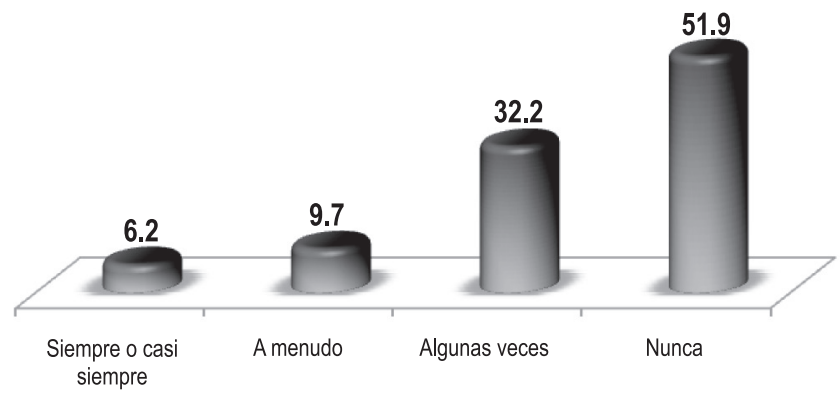

Figura $\mathrm{N}^{\circ} 20$

\section{TENGO DIFICULTADES PARA ESTABLECER RELACIONES INTERPERSONALES PROFUNDAS Y SATISFACTORIAS CON ALGUNAS PERSONAS (\%)}

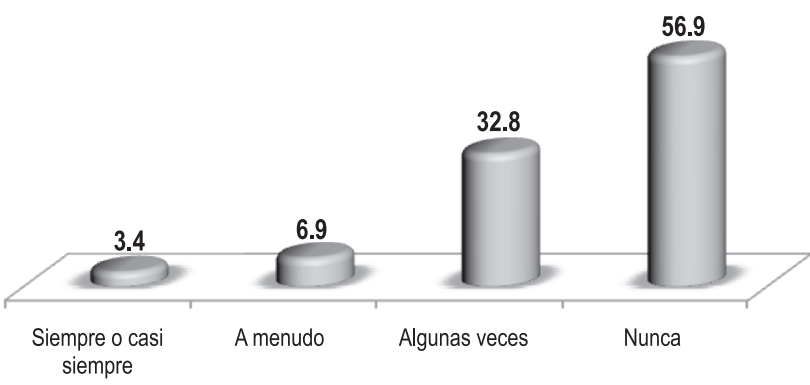

Fuente: Evaluación para conocer las competencias comunicativas y salud mental positiva de los profesores de Lima Metropolitana

Fuente: Evaluación para conocer las competencias comunicativas y salud mental positiva de los profesores de Lima Metropolitana 
Figura $\mathrm{N}^{\circ} 21$

Fuente: Evaluación para conocer las competencias comunicativas y salud mental positiva de los profesores de Lima Metropolitana

Fuente: Evaluación para conocer las competencias comunicativas y salud mental positiva de los profesores de Lima Metropolitana

\section{ME PREOCUPA MUCHO LO QUE LOS DEMÁS PIENSAN DE MI (\%)}

46.1

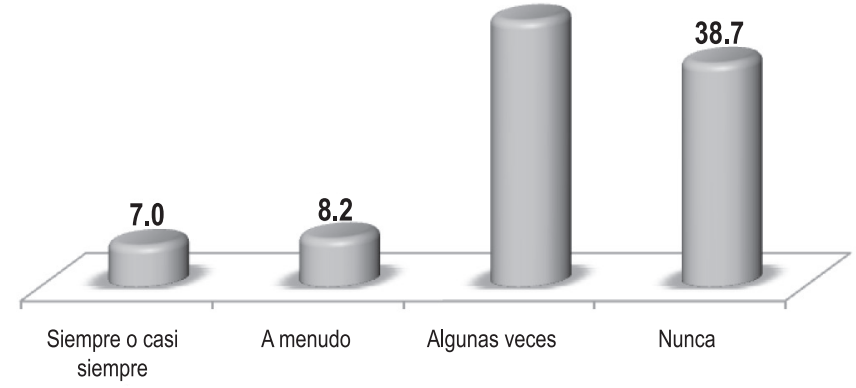

Figura $\mathrm{N}^{\circ} 22$

\section{CREO QUE TENGO MUCHA CAPACIDAD PARA PONERME EN LUGAR DE LOS DEMÁS Y COMPRENDER SUS RESPUESTAS (\%)}

35.7

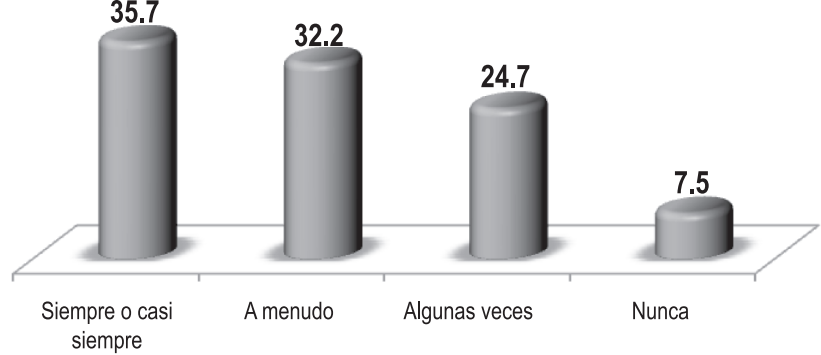

Figura $\mathrm{N}^{\circ} 23$
Fuente: Evaluación para conocer las competencias comunicativas y salud mental positiva de los profesores de Lima Metropolitana 
Figura $\mathrm{N}^{\circ} 24$

\section{LAS OPINIONES DE LOS DEMÁS ME INFLUYEN MUCHO A LA HORA DE TOMAR MIS DECISIONES (\%)}

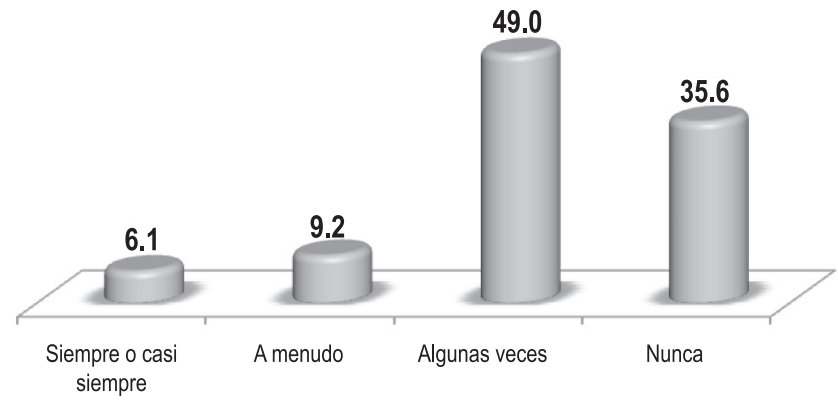

Fuente: Evaluación para conocer las competencias comunicativas y salud mental positiva de los profesores de Lima Metropolitana

Figura $\mathrm{N}^{\circ} 25$

\section{ME CONSIDERO UNA PERSONA MENOS IMPORTANTE QUE EL RESTO DE PERSONAS QUE ME RODEAN (\%)}

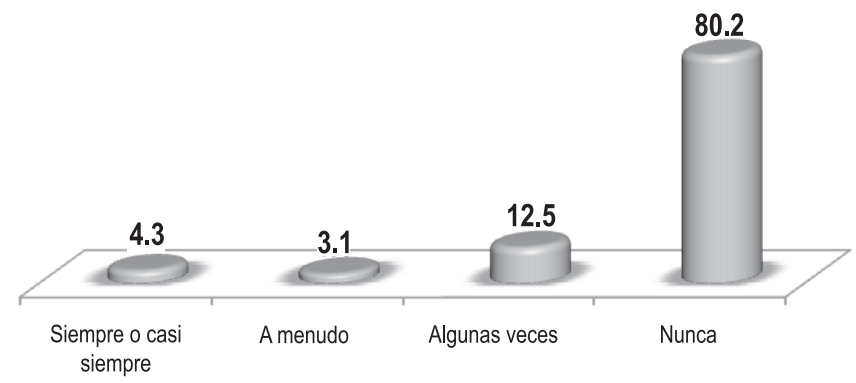

Fuente: Evaluación para conocer las competencias comunicativas y salud mental positiva de los profesores de Lima Metropolitana

Figura $\mathrm{N}^{\circ} 26$

SOY CAPAZ DE TOMAR DECISIONES POR MI MISMA/O (\%)

64.5

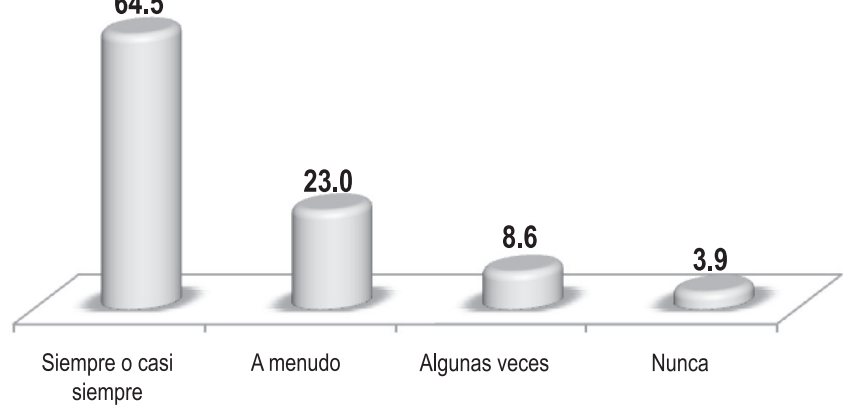

Fuente: Evaluación para conocer las competencias comunicativas y salud mental positiva de los profesores de Lima Metropolitana 
Figura $\mathrm{N}^{\circ} 27$

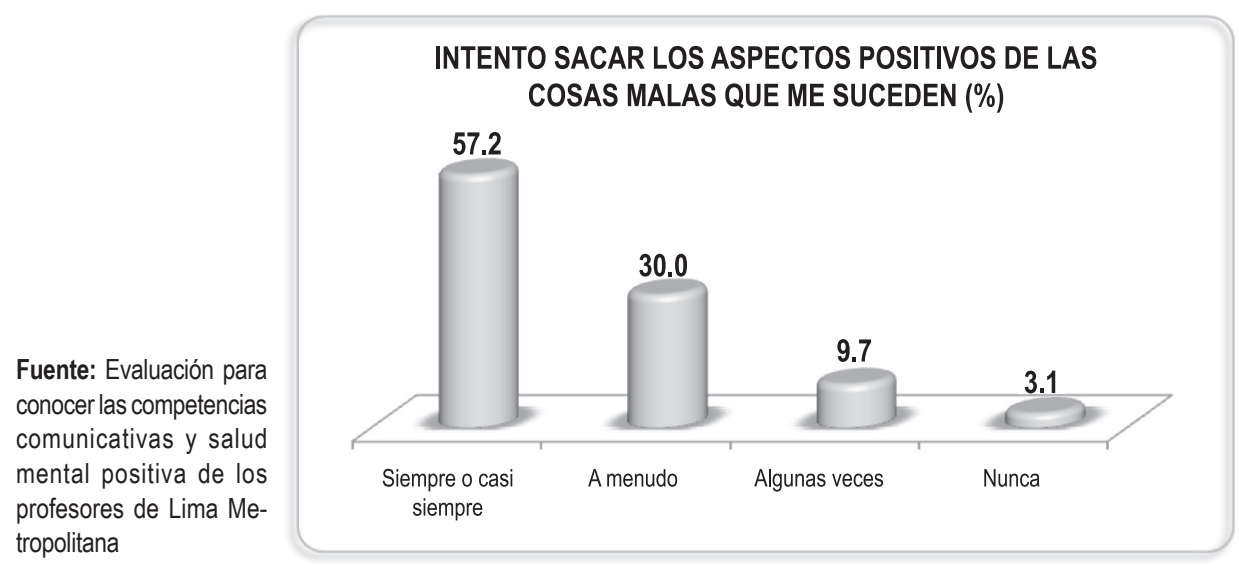

Figura $\mathrm{N}^{\circ} 28$

\section{INTENTO MEJORAR COMO PERSONA (\%)}

75.1

Fuente: Evaluación para conocer las competencias comunicativas y salud mental positiva de los profesores de Lima Metropolitana

Figura $\mathrm{N}^{\circ} 29$

ME CONSIDERO “UN/A BUEN/A PROFESOR/A" (\%)

59.4

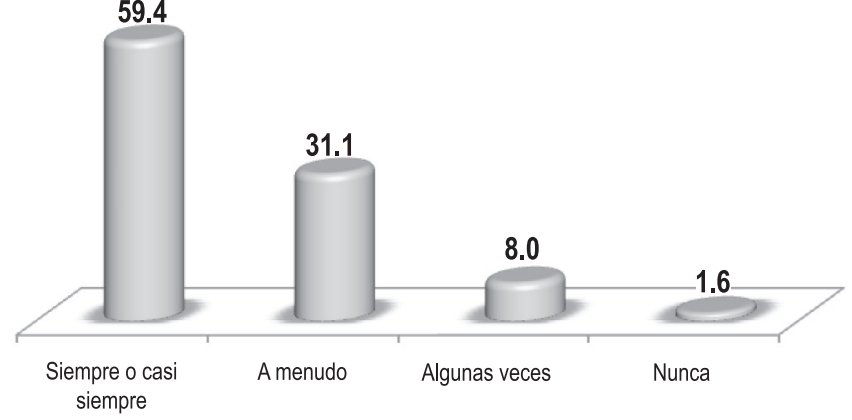

positiva de los profesores de Lima Metropolitana

Fuente: Evaluación para conocer las competencias comunicativas y salud

\section{5}

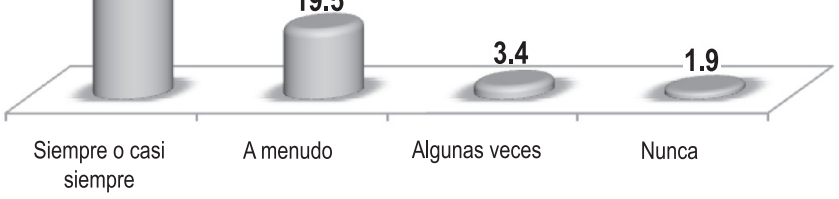


Figura $\mathrm{N}^{\circ} 30$

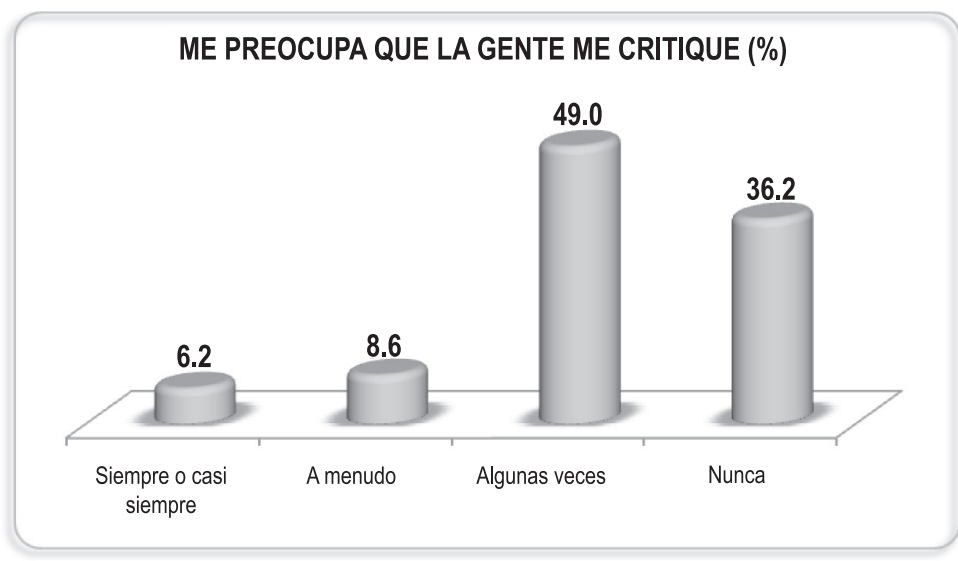

Fuente: Evaluación para conocer las competencias comunicativas y salud mental positiva de los profesores de Lima Metropolitana

Figura $\mathrm{N}^{\circ} 31$

\section{CREO QUE SOY UNA PERSONA SOCIABLE (\%)}

56.5

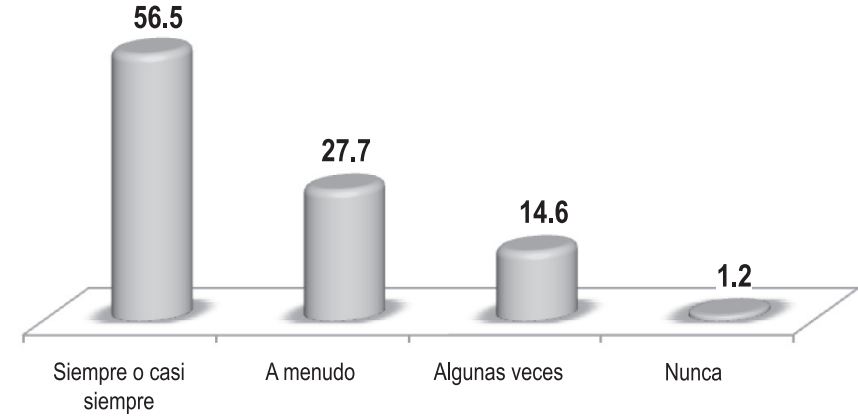

Fuente: Evaluación para conocer las competencias comunicativas y salud mental positiva de los profesores de Lima Metropolitana

La prueba de las competencias comunicativas han tenido los siguientes resultados:

RESULTADO - PRUEBA 1

\begin{tabular}{lrrrr}
\hline & Frecuencia & Porcentaje & Porcentaje válido & Porcentaje acumulado \\
\hline Primaria & 84 & 30,7 & 30,7 & 30,7 \\
Secundaria & 162 & 59,1 & 59,1 & 89,8 \\
Terciaria & 28 & 10,2 & 10,2 & 100,0 \\
Total & 274 & 100,0 & 100,0 & 28,1 \\
\hline \multicolumn{5}{c}{ RESULTADO - PRUEBA 2 } \\
\hline Primaria & Frecuencia & Porcentaje & Porcentaje válido & Porcentaje acumulado \\
Secundaria & 77 & 28,1 & 28,1 & 90,9 \\
Terciaria & 172 & 62,8 & 62,8 & 100,0 \\
Total & 25 & 9,1 & 9,1 & \\
\hline
\end{tabular}


RESULTADO - PRUEBA 3

\begin{tabular}{|c|c|c|c|c|}
\hline \multicolumn{2}{|c|}{ Frecuencia } & Porcentaje & Porcentaje válido & Porcentaje acumulado \\
\hline Primaria & 92 & 33,6 & 33,6 & 33,6 \\
\hline Secundaria & 164 & 59,9 & 59,9 & 93,4 \\
\hline Terciaria & 18 & 6,6 & 6,6 & 100,0 \\
\hline Total & 274 & 100,0 & 100,0 & \\
\hline \multicolumn{5}{|c|}{ RESULTADO - PRUEBA 4} \\
\hline & uencia & Porcentaje & Porcentaje válido & Porcentaje acumulado \\
\hline Primaria & 76 & 27,7 & 27,7 & 27,7 \\
\hline Secundaria & 177 & 64,6 & 64,6 & 92,3 \\
\hline Terciaria & 21 & 7,7 & 7,7 & 100,0 \\
\hline Total & 274 & 100,0 & 100,0 & \\
\hline \multicolumn{5}{|c|}{ DOMINANCIA } \\
\hline & Frecuencia & a Porcentaje & Porcentaje válido & Porcentaje acumulado \\
\hline Dominancia simple & 36 & 13,1 & 13,1 & 13,1 \\
\hline Dominancia Doble & 54 & 19,7 & 19,7 & 32,8 \\
\hline Dominancia Triple & 35 & 12,8 & 12,8 & 45,6 \\
\hline Dominancia Total & 20 & 7,3 & 7,3 & 52,9 \\
\hline Dominancia Media & 89 & 32,5 & 32,5 & 85,4 \\
\hline Sin dominancia & 40 & 14,6 & 14,6 & 100,0 \\
\hline Total & 274 & 100,0 & 100,0 & \\
\hline
\end{tabular}

\section{DISCUSIÓN}

Existen correlaciones significativas entre el puntaje de la Prueba 1, referida a la salud mental positiva con los siguientes factores:

Factor 1 (f1) satisfacción personal

N. ${ }^{\circ}$ 3. "A mí, me resulta especialmente difícil escuchar a las personas que me cuentan sus problemas" (Correlación positiva 0.197)

N. ${ }^{\circ} 4$. "Me gusto como soy" (Correlación negativa -0.238)

Factor 2 (f2) actitud pro social

N. ${ }^{\circ}$ 5. "Soy capaz de controlarme cuando tengo pensamientos negativos" (Correlación negativa -0.190 )

Factor 3 (f3) autocontrol

N. ${ }^{\circ}$ 2. "Los problemas me bloquean fácilmente" (Correlación positiva 0.244)

N. ${ }^{\circ}$ 10. "Me preocupa mucho lo que los demás piensan de mí" (Correlación positiva 0.156 ) 
N. ${ }^{\circ}$ 13. "Las opiniones de los demás me influyen mucho a la hora de tomar mis decisiones" (Correlación positiva 0.189)

N. ${ }^{\circ}$ 19. "Me preocupa que la gente me critique” (Correlación positiva 0.138)

Factor 4 (f4) autonomía

N. ${ }^{\circ}$ 15. Soy capaz de tomar decisiones por mi misma/o" (Correlación negativa $-0.164)$

Factor 5 (f5) resolución de problemas y auto actualización

N. ${ }^{\circ} 11$. "Creo que tengo mucha capacidad para ponerme en el lugar de los demás y comprender sus respuestas" (Correlación negativa -0.154)

N. ${ }^{\circ}$ 18. "Me considero un/a buen/ profesor/a" (Correlación negativa -0.236)

Factor 6 (f6) habilidades de relaciones interpersonales

N. ${ }^{\circ}$ 8. “A mí, me resulta especialmente difícil dar apoyo emocional” (Correlación positiva 0.157 )

N. ${ }^{\circ}$ 9. "Tengo dificultades para establecer relaciones interpersonales profundas y satisfactorias con algunas personas" (Correlación positiva 0.184)

N. ${ }^{\circ} 20$. “Creo que soy una persona sociable” (Correlación negativa -0.302)

Existen correlaciones significativas entre el puntaje de la Prueba 2 referida a competencias comunicativas, con los siguientes factores:

Factor 1 (f1) satisfacción personal

N. ${ }^{\circ}$ 3. "A mí, me resulta especialmente difícil escuchar a las personas que me cuentan sus problemas" (Correlación positiva 0.155)

N. ${ }^{\circ}$ 4. "Me gusto como soy" (Correlación negativa -0.215)

N. ${ }^{\circ}$ 6. "Me siento a punto de explotar" (Correlación positiva 0.167)

N. ${ }^{\circ}$ 7. "Para mí la vida es aburrida y monótona” (Correlación positiva 0.130)

Factor 2 (f2) actitud prosocial

N. ${ }^{\circ}$ 5. "Soy capaz de controlarme cuando tengo pensamientos negativos" (Correlación negativa -0.162 )

Factor 3 (f3) autocontrol

N. ${ }^{\circ}$. "Los problemas me bloquean fácilmente" (Correlación positiva 0.268) 
N. ${ }^{\circ}$ 13. "Las opiniones de los demás me influyen mucho a la hora de tomar mis decisiones" (Correlación positiva 0.147)

N. ${ }^{\circ}$ 19. "Me preocupa que la gente me critique" (Correlación positiva 0.190)

Factor 4 (f4) autonomía

N. ${ }^{\circ} 15$. Soy capaz de tomar decisiones por mi misma/o" (Correlación negativa $-0.181)$

Factor 5 (f5) resolución de problemas y auto actualización

N. ${ }^{\circ} 11$. "Creo que tengo mucha capacidad para ponerme en el lugar de los demás y comprender sus respuestas" (Correlación negativa -0.137)

N. ${ }^{\circ} 16$. "Intento sacar los aspectos positivos de las cosas malas que me suceden" (Correlación negativa -0.146)

N. ${ }^{\circ}$ 18. "Me considero un/a buen/ profesor/a" (Correlación negativa -0.208)

Factor 6 (f6) habilidades de relaciones interpersonales

N. ${ }^{\circ} 8$. "A mí me resulta especialmente difícil dar apoyo emocional” (Correlación positiva 0.175 )

N. ${ }^{\circ}$ 9. "Tengo dificultades para establecer relaciones interpersonales profundas y satisfactorias con algunas personas" (Correlación positiva 0.180)

N. ${ }^{\circ} 20$. "Creo que soy una persona sociable" (Correlación negativa -0.304)

Existen correlaciones significativas entre el puntaje de la Prueba 3 con los siguientes ítems:

Factor 6 (f6) habilidades de relaciones interpersonales

N. ${ }^{\circ} 20$. "Creo que soy una persona sociable" (Correlación negativa -0.147)

Existen correlaciones significativas entre el puntaje de la Prueba 4 con los siguientes ítems:

Factor 1 (f1) satisfacción personal

N. ${ }^{\circ}$ 4. "Me gusto como soy" (Correlación negativa -0.160)

Factor 6 (f6) habilidades de relaciones interpersonales

N. ${ }^{\circ} 20$. "Creo que soy una persona sociable" (Correlación negativa -0.149) 


\section{CONCLUSIONES}

Los puntajes de las competencias comunicativas (pruebas 1 y 2) presentan correlaciones significativas con la salud mental positiva; caso contrario de los puntajes de las pruebas 3 y 4 , los cuales prácticamente no muestran correlación con la salud mental positiva, lo que significa que se evidencia dominancias cruzadas de los hemisferios cerebrales que orientan la comunicación comunicativa en relación a la salud mental positiva, destacando casi uniformemente los hemisferios derecho e izquierdo; hecho que significa que se encuentra una hegemonía del hemisferio izquierdo y cerebral superior, predisponiendo hacia un perfil lógicoracional analítico y creativo-lógico; en el primer caso, permite un proceso de comunicación de tipo verbal y escrito caracterizado por un lenguaje simbólico y argumentativo ideal para la elaboración de ensayos científicos en el que priman los códigos elaborados del discurso de las ciencias; sin embargo, es necesario anotar que dicho perfil es de carácter dogmático y reduccionista; y en el segundo permite un proceso de comunicación tanto verbal como no verbal, pues en dicho perfil se da una comunicación media entre los dos hemisferios a través del cuerpo calloso. Debido a la capacidad sinérgica existen capacidades aunque reducidas de actuar tanto en el cuerpo del ensayo científico como en la poesía y la narrativa (el cuento), sin embargo, es un perfil que descuida lo humanístico, lo espiritual y la gestión de la complejidad humana.

Es importante destacar que en la salud mental positiva, específicamente el ítems 20 "Creo que soy una persona sociable" presenta correlaciones significativas y negativas con los cuatro puntajes de las pruebas de competencias comunicativas, recomendando profundizar el análisis de los resultados obtenidos en la presente investigación contrastándolos con otras investigaciones, para así contribuir a un mejor entendimiento de las competencia comunicativas con la salud mental positiva.

\section{REFERENCIAS BIBLIOGRÁFICAS}

Alles, Martha (2008) Selección de competencias. Buenos Aires. Granica.

Balbi, Juan (2004) La mente computacional. En La mente narrativa, hacia una concepción posracionalista de la identidad personal. Buenos Aires Paidós.

Balbi, Juan (2004) La mente narrativa. En La mente narrativa, hacia una concepción posracionalista de la identidad personal. Buenos Aires Paidós.

Carrión M. Juan (2008) Organizaciones idiotas vs organizaciones inteligentes. España: Prentice Hall.

Castell, Manuel (1998) La era de la información. Economía, sociedad y cultura. Vol 2. El poder de la identidad. España: Alianza Editorial.

Cuesta, Santos (2010) Gestión del talento humano y del conocimiento. Colombia: ECDE

Dublin, Nick (2012) El síndrome de Asperger y la ansiedad. México: Trillas. 
Ellis, Albert (1980) La teoría de la psicoterapia racional-emotiva. En Razón y emoción en Psicoterapia racional-emotiva. Bilbao: DDB, pp.37-57

Ellis, Albert (1980) Las ideas irracionales que causan y mantienen las perturbaciones emocionales. En Razón y emoción en Psicoterapia racional-emotiva. Bilbao: DDB, pp.59-82

Fromm, Erich (1992) La revolución de la esperanza. México: FCE.

Fromm, Erich (1982) Sobre la desobediencia. México: FCE.

Fromm, Erich (1983) El amor a la vida. México: FCE.

Fromm, Erich (1991) La condición humana actual Barcelona: Paidós

Glaserfeld, Von (1996) Aspectos del constructivismo radical. En Marcelo Pakman, construcciones de la experiencia humana. Volumen I. Barcelona: GEDISA

Gardner, Howard (1999) Las inteligencias múltiples. Estructura de la mente. México:FCE.

Golder, Mario (1980) Reportajes contemporáneos a la Psicología Soviética. Buenos Aires A. Cartago.

Kleiner, Art y Roth, G (2008) El cambio basado en el aprendizaje. México: Oxford.

Kerr, John (1995) Historia secreta del psicoanálisis. Barcelona: Grijalbo.

Lazzati, S (2008) El cambio del comportamiento en el trabajo. Granica.

Lyotard, Jean Francois (2003) La posmmodernidad, explicada a los niños. Barcelona: GEDISA.

Maslow Abrahan (2006) La aptitud de la naturaleza humana. México: Trillas

Miller, Jonathan (1986) Los molinos de la mente. Conversaciones con investigadores en Psicología. México: FCE.

Ortiz Cabanillas, Pedro (2010) Introducción a una psicobiología del hombre. Lima: UNMSM.

Parada, T.E. (2008) Psicología y emergencia. Habilidades psicológicas en las profesiones de socorro y emergencia. España: DECLEE

Ronco, E y Lladò, E (2000) Aprender a gestionar el cambio. Barcelona: Paidós

Rotondo, Humberto (1984) Introducción a las creencias del comportamiento. Lima: OKURA.

Schacter, Daniel (2011) Los siete pecados de la memorias. Barcelona: Ariel.

Schvarstein, Leonardo (2004) La inteligencia social de las organizaciones desarrollando las competencias necesarias para el ejercicio efectivo de la responsabilidad social. Buenos Aires Paidós.

Toffler, Alvin y Heidi (1995) La creación de una nueva civilización. La política de la tercera ola. España: Plaza y Janes.

Valdizán, Hermilio (1988) Locos de la colonia. Lima: INC. 